\title{
Crystallographic Orientation Observation and Mechanical Properties Evaluation of Fine-Grained Pure Aluminum*
}

\author{
Takashi SAKAI**, Tsuyoshi FURUSHIMA***, Ken-ichi MANABE***, \\ Hideo MORIMOTO**** and Eiji NAKAMACHI ${ }^{\dagger}$
}

\begin{abstract}
In order to improve the material characteristics of single and polycrystals of pure aluminum, the relationships between crystallographic orientations and microstructures, and the mechanical properties were examined. Several conventional grain-forming procedures, such as accumulative roll bonding (ARB), equal-channel angular pressing (ECAP) and accumulative forging bonding (AFB), were performed to obtain the ultrafine-grained structure. Furthermore, some analytical results, such as crystal direction maps, inverse pole figure (IPF), and texture, were obtained from the SEM-electron backscattered diffraction pattern (EBSP). As a result, (1) for the ARB method, increases of strength and ductility were shown, since the cube orientation was developed; (2) for the ECAP method, in the extrusion direction (ED) plane at the die angle $\Psi=100^{\circ}$, peculiar distributions of microstructure and hardness were obtained; (3) for the AFB method, stratified inclination microstructures were obtained, and thus the typical texture was also observed.
\end{abstract}

Key Words: Hardness, Material Testing, Grain Refinement, Crystallographic Orientation, SEM-EBSP Apparatus, Microstructure, Single Crystal, Pure Aluminum

\section{Introduction}

Lately, research and development on material synthesis processes using microstructure control have been conducted as a means of improving the mechanical properties and formability of metallic materials. This concept is represented by the addition of second and third alloying elements for grain refinement ${ }^{(1)}$, and the crystal structure concept. However, many little-understood issues remain regarding microscopic factors in the material structure. Those issues, if resolved, would contribute to enhanced mechanical properties or formability of material.

* Received 4th July, 2005 (No. 05-4088)

** Department of Mechanical Engineering, Takamatsu National College of Technology, 355 Chokushi, Takamatsu, Kagawa 761-8058, Japan.

E-mail: sakai@takamatsu-nct.ac.jp

*** Department of Mechanical Engineering, Tokyo Metropolitan University, 1-1 Minami-osawa, Hachioji, Tokyo 192-0397, Japan

**** Furukawa Electric Co., Ltd., 2-4-3 Okano, Nishi-ku, Yokohama, Kanagawa 220-0073, Japan

$\dagger$ Department of Mechanical Engineering, Osaka Institute of Technology, 5-16-1 Omiya, Asahi, Osaka 535-8585, Japan
Therefore, behavior and combination effects are investigated first in this study. In the traditional research on grain refinement, the main targets are grain refinement to the nanolevel ${ }^{(2),(3)}$ and proposals of new refinement methods ${ }^{(4)-(6)}$, for example.

We consider that meaningful improvement of the plastic deformation property of a material requires material design that takes into consideration the stress state at each position, as well as an understanding of the microscopic behavior of the material. That is, it is essential to apply the concept of "the right microstructure in the right place", rather than "the right material in the right place", in common structural materials. Although there are some experimental results for the microbehavior of iron and steel ${ }^{(7),(8)}$, there are only a few results for alu$\operatorname{minum}^{(9)}$.

As the first step, we specifically addressed grain refinement, which is presumed to enable high strength and excellent ductility, within this background. Furthermore, through experimentation, we investigated the effect of the change of microstructured specimens, subjected to refinement in various strain-charge modes, on the dynamic properties.

In particular, the aim of this study is to elucidate the fundamental mechanical properties of grained pure alu- 
minum. Relationships among, for example, mechanical properties, grain properties and crystallographic orientation properties, were investigated for this grained pure aluminum. The fundamental experimental data obtained is applied to construct a basic database of grained materials.

\section{Strain-Charge Modes and Specimens}

The following three refining techniques were employed for specimen preparation in this study to investigate the effect of strain-charge modes on microstructure: (a) accumulative roll bonding (ARB) using repetitive weld rolling, (b) equal-channel angular pressing (ECAP), which extrudes a specimen through channels crossing a die, and (c) accumulative forging bonding (AFB) using repetitive weld forging. Equivalent strain $\bar{\varepsilon}$ for one pass in each technique was taken to be $0.8^{(10)}, 0.9^{(11)}$, and 0.7 , respectively, from references.

Single-crystal pure aluminum oriented in the [001] direction for easy crystal orientation observation, and polycrystalline pure aluminum (JIS A1100) annealed in air at $623 \mathrm{~K}$ for $1.8 \mathrm{ks}$ were employed as samples. Specimens prepared for intensive deformation had the dimensions of $1 \mathrm{~mm} \times 20 \mathrm{~mm} \times 30 \mathrm{~mm}$ for ARB and AFB, and $10 \mathrm{~mm}$ diameter and $30 \mathrm{~mm}$ height for ECAP.

3. Microstructure Observation and Crystal Orientation Observation by SEM-EBSP (Electron Backscattered Diffraction Pattern) Analysis

\subsection{ARB method}

As an example of specimens subjected to ARB, the microstructure along the ND plane of 5ARB-s (a singlecrystal specimen subject to ARB for five passes), and the inverse pole figure obtained by orientation analysis of this specimen using the SEM-EBSP, are shown in Fig. 1. The average grain size of isometrically arranged grains was estimated to be about $D \fallingdotseq 60 \mu \mathrm{m}$ from the microstructure by the intercept method. Furthermore, the inverse pole figure revealed that the continuous strain charge caused crystal orientations to be aligned to [001]//ND and [001]//RD.

\subsection{ECAP method}

As an example of specimens subjected to ECAP, the microstructure at the center of the ED plane of the 1ECAP-s specimen and its inverse pole figure are shown in Fig. 2. Equiaxial grains of $D=250 \mu \mathrm{m}$ were formed in the upper part of the specimen, which passed along the inner wall of the channel. On the other hand, deformation bands were observed in the lower part of the specimen, which passed along the outer wall of the channel, but there was no grain formation. This results from the fact that different shear strain is induced in each part of the crossing channels. In addition, uniform grains were observed in 5ECAP-s, to which Route $\mathrm{B}_{\mathrm{c}}{ }^{(12)}$ was applied, and 5ECAP-p, whose grain sizes were $D=42 \mu \mathrm{m}$ and $14 \mu \mathrm{m}$, respectively. Few dominant orientations were found because there was much dispersion.

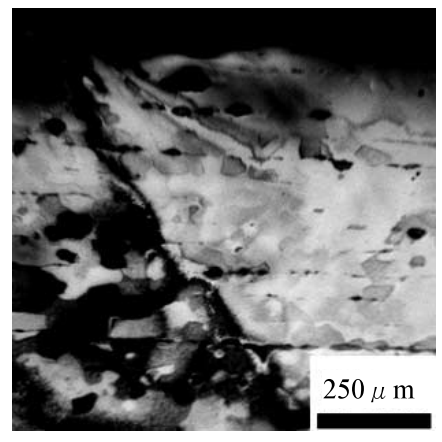

(a) Optical micrograph, $D \fallingdotseq 60 \mu \mathrm{m}$

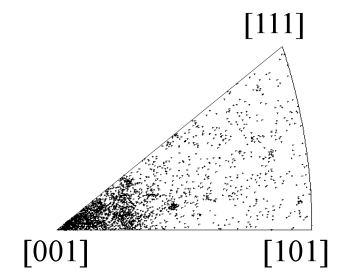

(b) ND plane

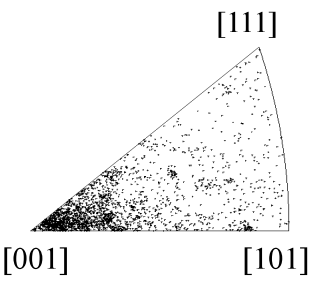

(c) RD plane

Fig. 1 Micrograph and inverse pole figures of ND plane of 5ARB-s specimen

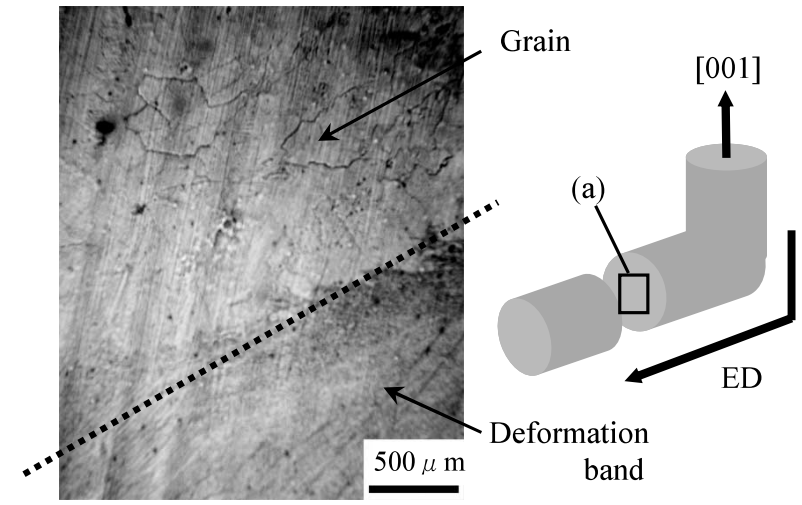

(a) Optical micrograph
[111]

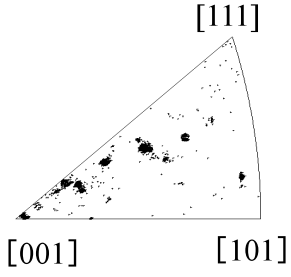

(b) ND plane (upper)

[111]

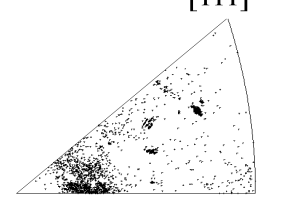

[001]

(d) ND plane (lower)

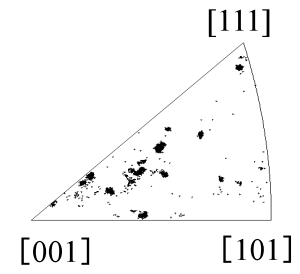

(c) RD plane (upper)

[111]

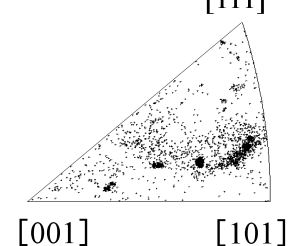

(e) RD plane (lower)

Fig. 2 Micrograph and inverse pole figures at center of ED plane of 1ECAP-s specimen 


\subsection{AFB method}

Figure 3 shows the microstructure and inverse pole figure on the CD plane of 1AFB-s. Grains and deformation bands tilt counterclockwise to $\mathrm{RD}$ by about $60^{\circ}$ in the upper part of the joint plane and clockwise by about $60^{\circ}$ in the lower part. The orientation is aligned to [112]//ND and $[114] / /$ RD. Moreover, the number of layers and the tilting angle of a grain are controllable by this technique via the number of passes. Elongated grains with no tilting angle were obtained in 5AFB-s. Thus, it is presumed that AFB is suitable for controlling texture because the crystal

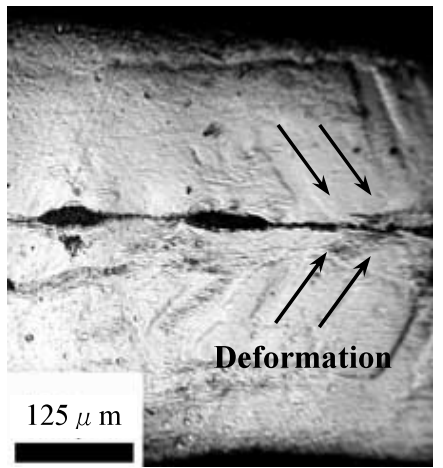

(a) Optical microscope

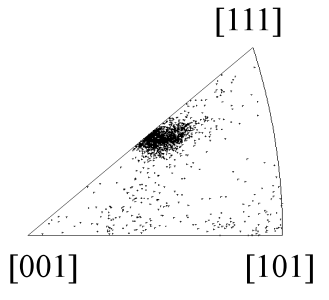

(b) ND plane

[111]

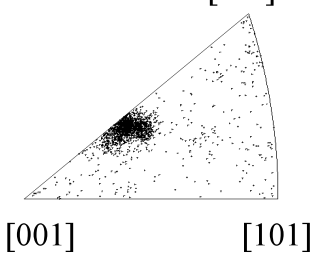

(c) RD plane
Fig. 3 Micrograph and inverse pole figures of CD plane of 1AFB-s specimen
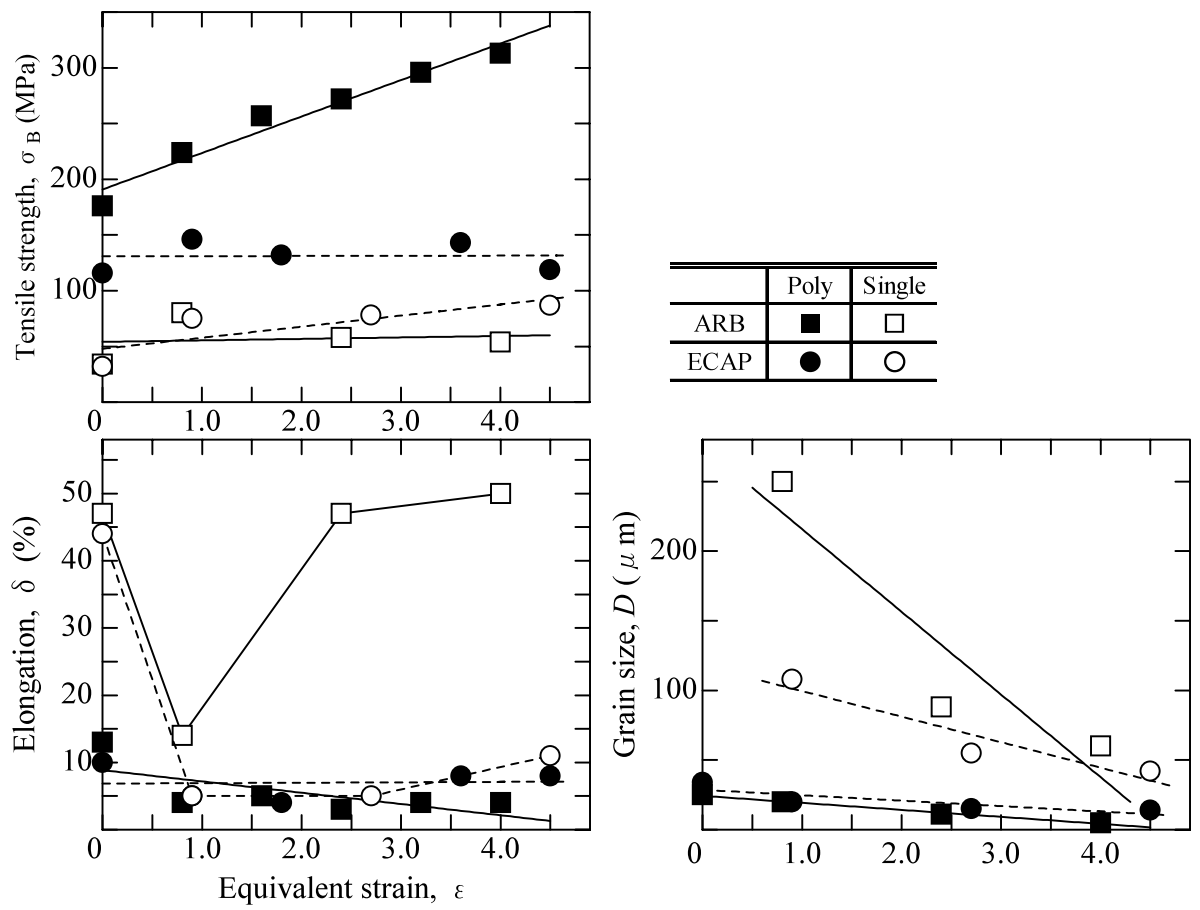

Fig. 4 Relationships of tensile strength, elongation and grain size with equivalent strain for

ARB and ECAP specimens

rotation can be easily controlled.

\section{Crystal Orientation and Mechanical Properties}

To investigate the effect of crystal orientation and equivalent strain on the mechanical properties of the material, a tensile test at a cross-head speed of $0.2 \mathrm{~mm} / \mathrm{min}$ and a micro-Vickers hardness test at an indenter load of $1 \mathrm{~N}$ with $10 \mathrm{~s}$ retention time were carried out at room temperature in air. The results are shown in Fig. 4 and Table 1, respectively.

The tensile strength of 5ARB-s is $\sigma_{B}=55 \mathrm{MPa}$, which is about twice that of OARB-s, whereas its elongation is $\delta=50 \%$, almost equivalent to that of OARB-s, as shown in Fig. 4. This results from the alignment of the orientation to [001]//ND and [001]//RD, as shown in the inverse pole figures in Fig. 1 (b) and (c). Although each mechanical property at the equivalent strain of ARB-s shows different behavior from those of ARB-p, few variations in orientation are caused by rolling. It is inferred that the orientation changed through dynamic recrystallization during deformation in some specimens with low recrystallization

Table 1 Numerical list of Vickers hardness for ECAP specimens

\begin{tabular}{c|c|c|c|c}
\hline \hline \multirow{2}{*}{ specimen } & \multirow{2}{*}{$\begin{array}{c}\text { Equivalent } \\
\text { strain }\end{array}$} & \multicolumn{3}{|c}{ Micro-Vickers hardness } \\
\cline { 3 - 5 } & & Upper & Center & Lower \\
\hline 0ECAP-s & 0.0 & 20.5 & 20.5 & 20.4 \\
\hline 1ECAP-s & 0.9 & 16.9 & 33.9 & 28.2 \\
\hline 3ECAP-s & 2.7 & 26.3 & 24.2 & 20.4 \\
\hline 5ECAP-s & 4.5 & 32.9 & 33.5 & 30.8 \\
\hline
\end{tabular}

\begin{tabular}{c|c|c}
\hline \hline & Poly & Single \\
\hline ARB & $\mathbf{a}$ & $\square$ \\
\hline ECAP & $\bullet$ & $\bigcirc$ \\
\hline
\end{tabular}


temperatures.

The $0.2 \%$ proof stresses of the ARB and ECAP specimens obey the Hall-Petch law, and increase with the decrease of the grain size.

The hardness test result for ECAP-s in Table 1 indicates that hardness was lowest at $H v=16.9$ in the upper part in which a grain was formed, as shown in Fig. 2, and the highest at $H v=33.9$ in the center. This is inferred to result from the high shear strain accumulated by deformation in the upper part, which caused dynamic recrystallization. Moreover, in the central part, because little strain was introduced to induce recrystallization, the increased hardness is presumed to be the result of strain hardening.

In the ARB, ECAP and AFB methods strain is added by rolling, sharing and forging, respectively. However, unfortunately, detailed mechanisms of each strain-charge mode on microstructure are not clear for the data obtained in this study. Furthermore, the relationship between the formation of fine grains and dislocations is also still unclear. With the construction of a database for fine grains of single and polycrystals, the details of these mechanisms will become clear.

\section{Conclusions}

(1) ARB-s specimens demonstrate elongation improvement as well as tensile strength and hardness, in connection with grain refinement. This is due to the crystal orientation alignment to [001]//ND and [001]//RD with increasing number of deformation passes.

( 2 ) Although uniform fine grains are obtained by applying Route $\mathrm{Bc}$ in the ECAP method, the charge of uneven strain causes difficulty in orientation control.

(3) The AFB method forms an inclined lamellar structure; therefore, the tilting angle can be controlled by introducing a deformation cycle.

\section{Acknowledgement}

This work was supported by Grant-in-Aid for Scientific Research \#14655274 sponsored by Japan Society for the Promotion of Science.

\section{References}

( 1 ) Yoshida, Y., Yamada, H., Kamado, S. and Kojima, Y., Tensile and Low Temperature Superplasticity of Mg-Li-Zn Alloy Formed by ECAE Method, J. Japan
Inst. Light Metals, (in Japanese), Vol.51, No.10 (2001), pp.551-555.

( 2 ) Kawamura, Y. and Inoue, A., The Trend and Prospects for Nanocrystalline Light Metals with Ultra-High Strength, Materia Japan, (in Japanese), Vol.41, No.6 (2002), pp.414-417.

( 3 ) Oishi, K., Kaneko, K. and Horita, Z., Nano-Structural Control Using Severe Plastic Deformation, Materia Japan, (in Japanese), Vol.41, No.6 (2002), pp.422-426.

( 4 ) Cui, Q. and Ohori, K., Grain Refinement of a 6061 Aluminum Alloy by Asymmetric Warm-Rolling, J. Japan Inst. Light Metals, (in Japanese), Vol.52, No.4 (2002), pp.185-189.

( 5 ) Ameyama, K., Grain Refinement and High Strength by Powder Metallurgy Process, J. Japan Soc. Tech. Plasticity, (in Japanese), Vol.39, No.452 (1998), pp.911914.

( 6 ) Xiang, S., Matsuki, K., Takatsuji, N., Tokizawa, M., Yokote, T., Kusui, J. and Yokoe, K., Microstructure and Mechanical Properties of PM 2024Al-3Fe-5Ni Alloy Consolidated by a New Process, Equal Channel Angular Pressing, J. Mat. Sci. Letters, Vol.16 (1997), pp.1725-1727.

( 7 ) Takaki, S., Nano-Structure Control in Iron and Steel Materials, Materia Japan, (in Japanese), Vol.41, No.6 (2002), pp.418-421.

( 8 ) Kimura, Y. and Takaki, S., Microstructures and Mechanical Properties of Ultra-Grained Steels by Mechanical Milling Method, J. Japan Soc. Tech. Plasticity, (in Japanese), Vol.41, No.468 (2000), pp.554-558.

( 9 ) Noda, M., Hirohashi, M., Funami, K., Suwahara, Y. and Kobayashi, M., Effect of Strain Loading Process on Grain Refinement in Aluminum Alloy, J. Japan Inst. Metals, (in Japanese), Vol.66, No.2 (2002), pp.101108.

(10) Lee, S.H., Inagaki, H., Utsunomiya, H., Saito, Y. and Sakai, T., Ultra Grain Refinement of Commercial Purity Aluminum by a Multi-Stack ARB Process, J. Japan Inst. Metals, (in Japanese), Vol.66, No.5 (2002), pp.470-475.

(11) Iwahashi, Y., Wang, J., Horita, Z, Nemoto, M. and Langdon, T.G., Principle of Equal-Channel Angular Pressing for the Processing of Ultra-Fine Grained Materials, Scripta Materialia, Vol.35, No.2 (1996), pp.143-146.

(12) Furukawa, M., Horita, Z., Nemoto, M. and Langdon, T.G., Grain Refinement and Superplasticity by ECAP Method, J. Japan Inst. Metals, (in Japanese), Vol.70, No.11 (2000), pp.218-225. 